\title{
Assessment of Health Literacy and Numeracy Among Spanish- speaking Parents of Young Children; Validation of the Spanish Parental Health Literacy Activities Test (PHLAT Spanish)
}

\author{
H. Shonna Yin, MD, MS ${ }^{1}$, Lee M. Sanders, MD, MPH ${ }^{2}$, Russell L. Rothman, MD, MPP ${ }^{3}$, Alan \\ L. Mendelsohn, MD ${ }^{1}$, Benard P. Dreyer, MD ${ }^{1}$, Richard O. White, MD $^{4}$, Joanne P. Finkle, JD, \\ RN $^{5}$, Stefania Prendes, BS $^{2}$, and Eliana M. Perrin, MD, MPH ${ }^{5}$ \\ ${ }^{1}$ Department of Pediatrics, NYU School of Medicine, New York, NY \\ 2University of Miami Miller School of Medicine, Miami, FL \\ ${ }^{3}$ Departments of Pediatrics and Internal Medicine, Vanderbilt University Medical Center, \\ Nashville, TN \\ ${ }^{4}$ Department of Pediatrics, Meharry Medical College, Nashville, TN \\ ${ }^{5}$ Department of Pediatrics, University of North Carolina at Chapel Hill School of Medicine, Chapel \\ Hill, NC
}

\begin{abstract}
Objective-To assess the health literacy and numeracy skills of Spanish-speaking parents of young children and to validate a new Spanish language health literacy assessment for parents, the Spanish Parental Health Literacy Activities Test (PHLAT-10 Spanish).
\end{abstract}

Design/Methods-Cross-sectional study of Spanish-speaking caregivers of young children ( $<30$ months) enrolled at primary care clinics in 4 academic medical centers. Caregivers were administered the 10-item PHLAT in addition to validated tests of health literacy (S-TOFHLA) and numeracy (WRAT-3 Arithmetic). Psychometric analysis was used to examine item characteristics of the PHLAT-10 Spanish, to assess its correlation with sociodemographics and performance on literacy/numeracy assessments, and to generate a shorter 8-item scale (PHLAT-8).

\begin{abstract}
Results-Of 176 caregivers, $77 \%$ had adequate health literacy (S-TOFHLA), while only $0.6 \%$ had $9^{\text {th }}$ grade or higher numeracy skills. Mean PHLAT-10 score was $41.6 \%$ (SD 21.1). Fewer than half $(45.5 \%)$ were able to read a liquid antibiotic prescription label and demonstrate how much medication to administer within an oral syringe. Less than a third (31.8\%) were able to interpret a food label to determine whether it met WIC guidelines. Higher PHLAT-10 score was associated with higher years of education ( $\mathrm{r}=0.49)$, S-TOFHLA ( $\mathrm{r}=0.53)$ and WRAT- $3(\mathrm{r}=0.55)$ scores $(\mathrm{p}<0.001)$. Internal reliability was good $(\mathrm{KR}-20=0.61)$. An 8 -item scale was highly correlated with the full 10-item scale $(\mathrm{r}=0.97, \mathrm{p}<0.001)$, with comparable internal reliability $(\mathrm{KR}-20=0.64)$.
\end{abstract}

\footnotetext{
(C) 2011 Academic pediatric Association. Published by Elsevier Inc. All rights reserved.

CORRESPONDENCE: H Shonna Yin, MD, MS, New York University School of Medicine, Department of Pediatrics, 550 First Avenue, NBV 8S4-11, New York, NY 10016, Telephone: (212) 562-2821; Fax: (212) 263-8172, yinh02@ med.nyu.edu.

Publisher's Disclaimer: This is a PDF file of an unedited manuscript that has been accepted for publication. As a service to our customers we are providing this early version of the manuscript. The manuscript will undergo copyediting, typesetting, and review of the resulting proof before it is published in its final citable form. Please note that during the production process errors may be discovered which could affect the content, and all legal disclaimers that apply to the journal pertain.
}

CONFLICTS OF INTEREST: The authors have no conflicts of interest to disclose. 
Conclusions-Many Spanish-speaking parents have difficulty carrying out health-related literacy and numeracy tasks. The Spanish PHLAT demonstrates good psychometric characteristics and may be useful for identifying parents who would benefit from receiving low-literacy child health information.

\section{Keywords}

anticipatory guidance; parenting skills; infants; health literacy

\section{INTRODUCTION}

The issue of low health literacy has significant implications for pediatric health, as at least 1 in 4, or over 21 million, US parents have limited health literacy. ${ }^{1}$ Parents use health literacy skills on a daily basis to care for their children, as they seek to understand the health information they encounter from such sources of information as health providers, peers, and the mass media. ${ }^{1,2}$ Health literacy tasks involving quantitative or numeracy skills, such as looking at nutrition labels to determine appropriate portion size, dosing liquid medications, and mixing infant formula, may be particularly difficult for parents. ${ }^{3,4}$

Health literacy is "the degree to which individuals have the capacity to obtain, process, and understand basic health information and services needed to make appropriate health decisions." ${ }^{5}$ It is distinguished from literacy in its focus on health-related issues, and its inclusion of a "functional" component related to ability to act on and apply health information, including the ability to access and navigate the health care system. ${ }^{6}$ The link between low health literacy and poor health behaviors and outcomes is well established. ${ }^{1,6-12}$ As health literacy is recognized as a key quality and safety by the Agency for Healthcare Research and Quality (AHRQ), Joint Commission, and the American Medical Association (AMA), ${ }^{7,8,13}$ the ability to assess individual health literacy skills has become a growing area of focus. In 2009, the topic of health literacy measurement served as the subject of a workshop hosted by the Institute of Medicine's Roundtable on Health Literacy. ${ }^{14}$

Until recently, with the development of the Parental Health Literacy Assessment Test (PHLAT) ${ }^{2}$ no scale has focused on measuring the health literacy skills of parents of young children. The vast majority of existing assessments remain largely focused on adult healthrelated tasks, despite recognition that assessments which target specific populations and skills may be beneficial. ${ }^{15-17}$ Studies have suggested that the Test of Functional Health Literacy in Adults (TOFHLA), ${ }^{18}$ one of the most frequently used and validated health literacy assessments in research, ${ }^{7}$ may not be optimal for younger cohorts of adults like parents of young children because a ceiling effect has been noted by researchers for this younger population. ${ }^{19-21}$

Latinos represent one of the fastest growing ethnic groups in the US, ${ }^{22}$ as well as a group considered to be at particular risk for problems associated with low health literacy. ${ }^{23}$ While there has been limited examination of the health literacy of Latino parents, one study revealed that Latino parents are more than twice as likely to be categorized as having low health literacy compared to white non-Hispanic parents, ${ }^{1}$ with implications for decreased access to care and poor health outcomes. Recent studies have also suggested that health literacy may serve as an important mediator of racial/ethnic health disparities. ${ }^{1,24}$ Availability of health literacy assessments in Spanish is therefore critically important.

The PHLAT ${ }^{2}$ was developed specifically to examine the health literacy of English-speaking parents of young children. A prior study of the PHLAT suggested utility of this tool as an 
assessment of functional parent health literacy in English; no previous psychometric assessments have been performed in Spanish. In this study, we therefore sought to examine the health literacy and numeracy of Spanish-speaking parents, as well as to validate the Spanish version of the PHLAT assessment.

\section{METHODS}

A cross-sectional study was performed at pediatric clinics in four academic institutions to examine the literacy and numeracy skills of Spanish-speaking caregivers, as well as to validate a Spanish version of the PHLAT. Institutional review board approval was obtained at each of the four institutions. Participants provided written informed consent, and were given a nominal reimbursement for their time.

\section{Scale development}

Information on scale development of the PHLAT has been previously described in detail. ${ }^{2}$ The PHLAT scale is designed to evaluate the health literacy skills of caregivers of young children, including numeracy skills. Skills tested as part of the assessment include understanding how to mix formula, measure the correct dose of medication, and how to read a nutrition label to determine whether a food is appropriate for their child.

Scale development was guided by a panel of experts in general pediatrics, health services research, pharmacy, psychology, public health, and health literacy, as well as by parents. The development process was also informed by a review of previously validated assessments of literacy and numeracy, including the TOFHLA ${ }^{18}$ and the Wide Range Achievement Test (WRAT). ${ }^{25}$

The original 20-item English version of the PHLAT demonstrated good reliability $($ KR-20 $=0.76)$ and construct validity (correlation with S-TOFHLA $(r=0.38 ; p<0.001)$, WRAT-3 $(\mathrm{r}=0.55, \mathrm{p}<0.001)$ ). A shortened version of the original 20-item PHLAT, consisting of 10 items, called the PHLAT-10, had a high correlation with the full PHLAT $(\mathrm{r}=0.91, \mathrm{p}<0.001)$, comparable construct validity, and maintained good internal reliability $(K R-20=0.70)$. This 10 item PHLAT retained 7 items focused on nutrition, 1 item on understanding a growth chart, and 2 items on medication dosing and its validity and reliability were recently reported. ${ }^{2}$

Unlike the original English-language PHLAT, the Spanish-language version of the PHLAT tested in this study used 2-dimensional images and labels, rather than actual, 3-dimensional products (sample items shown in Appendix 1). This change was made to allow the test to be administered more feasibly in clinical and research settings. Each image and label was adapted from a product similar to what parents typically encounter in caring for their child. For each image or label not already available in Spanish, a process of translation and backtranslation was used to generate a Spanish-language version, with a focus on ensuring translation of meaning and maintenance of context. This was meant to ensure that the PHLAT Spanish would specifically assess health literacy, rather than English-language proficiency. To maintain the look and feel of the original product, however, the images and fonts from the original retail products were retained.

\section{Study setting and participants}

From March through September 2009, a convenience sample of participants was recruited from pediatric clinics at four academic medical institutions that serve a diverse population of Latino families whose national origins include Central America, South America and the Caribbean, as well as a large proportion of patients from low socioeconomic status backgrounds. During clinic hours, Monday thru Friday, research assistants approached 
eligible study subjects as they waited with their children to be seen for a pediatric clinical encounter. All participants were consented according to institution-specific IRB protocols. Parents or legal guardians were eligible to participate if they were the primary caregiver of a child $<30$ months and spoke Spanish (English proficiency not required). Exclusion criteria included visual impairment (defined by having a corrected vision worse than 20/50 as assessed by a Rosenbaum Pocket Vision Screener) or presence of dementia or other serious mental illness. The term parents will be used to encompass both parents and legal guardians for the remainder of this paper.

\section{Assessments}

All assessments were conducted in Spanish and consisted of 5 parts: 1) a demographic questionnaire, 2) a validated health literacy measure (S-TOFHLA), ${ }^{26} 3$ ) a validated measure of arithmetic skills (WRAT-3), ${ }^{25}$ 4) 2 questions on self-reported health literacy skill, ${ }^{27}$ and, 5) the PHLAT-10 Spanish.

Sociodemographic data included caregiver age, country of origin, ethnicity, English proficiency, education level, relationship to the child, and ages of children, and were obtained using a structured questionnaire administered by a trained research assistant. A subject was categorized as having limited English proficiency if he or she did not report speaking English "very well."28

Health literacy was measured using the Spanish version of the 36-item short TOFHLA (STOFHLA); ${ }^{26}$ the S-TOFHLA is of the most frequently used measures in health literacy research. No numeracy items are included on the 36-item short TOFHLA. Caregivers were categorized as having inadequate (0-16), marginal (17-22), or adequate (23-36) functional health literacy, as specified in the TOFHLA manual. ${ }^{26}$

Caregiver quantitative skills were assessed using the WRAT-3 Arithmetic portion, a nationally used assessment of numeracy. The WRAT-3 Arithmetic consists largely of numerical equations, with limited English text. Portions written in English were translated into Spanish using a process of translation and back translation. Using the grade scores designated in the WRAT administrative manual, ${ }^{25}$ caregivers were categorized into the following grade levels: $5^{\text {th }}$ grade or less, $6^{\text {th }}$ to $8^{\text {th }}$ grade, and $9^{\text {th }}$ grade or higher.

Finally, parent self-reported health literacy skill was assessed using the following two questions adapted from Chew, et $\mathrm{al}^{27}: 1$ ) "How confident are you filling out medical forms by yourself?," with answer choices of "extremely," "quite a bit," "somewhat," "a little bit," and "not at all;" and, 2) "How often do you have someone help you read medical information?," with answer choices of "never," "occasionally," "sometimes," "often," and "always." These questions were included to enhance our ability to assess the construct validity of the PHLAT.

Bilingual research assistants who collected the data were trained by one of the authors (SY, RR, LS, EP, RW, JF), with periodic review and observation to ensure that data was collected in a reliable manner. Research assistants underwent training to be sensitive to the needs of populations with low literacy, including an emphasis on being nonjudgmental and supportive. In particular, research assistants were trained to encourage participants to try their best on the literacy and numeracy assessments.

\section{Analyses}

Data was analyzed using SPSS 18.0 (SPSS Inc., Chicago, IL). Descriptive analyses were conducted for all variables, including each of the individual items of the PHLAT. Health literacy, assessed using the S-TOFHLA, was analyzed as a continuous raw score, as well as 
categorically. Numeracy, measured using the WRAT-3 Arithmetic, was also analyzed both continuously as a standard score, as well as categorically, by grade level.

Total PHLAT-10 Spanish score was calculated as the percent of questions answered correctly. Construct validity was examined by performing bivariate analyses between PHLAT-10 Spanish score and caregiver characteristics as well as caregiver health literacy and numeracy skills. Spearman rank correlation coefficients were used to examine correlations between PHLAT-10 Spanish performance and continuous outcomes (education, S-TOFHLA raw score, WRAT-3 Arithmetic standard score). For categorical variables, mean score on the PHLAT-10 Spanish was compared using Student $t$ tests or one-way analysis of variance.

Internal reliability was assessed using the Kuder-Richardson coefficient of reliability (KR-20), a variation of Cronbach's alpha for dichotomous outcomes. Psychometric analyses were performed to examine factor loading through principal components analysis. An 8-item PHLAT (PHLAT-8) Spanish was created by retaining the items with the highest factor loadings, and removal of an item which was no longer clinically relevant. Correlation between the PHLAT-10 Spanish and PHLAT-8 Spanish was assessed using Spearman rank correlation. In addition, construct validity and internal reliability of the PHLAT-8 Spanish was assessed in the same manner described above for the PHLAT-10 Spanish.

\section{RESULTS}

One hundred and eighty-four caregivers were enrolled. Approximately $70 \%$ of approached eligible subjects agreed to participate; refusals were primarily due to concern re: missing their appointment. Eight caregivers did not complete the full assessment, due to time constraints. Data from the remaining 176 parents were included in analyses. Baseline characteristics of the enrolled parents are presented in Table 1. The mean age of parent's youngest child was 8.9 months (SD 7.2). Most parents (94.3\%) were born outside of the US. Approximately 1 in 5 parents $(22.7 \%$ ) had inadequate or marginal health literacy, as measured by the S-TOFHLA, nearly all parents $(99.4 \%)$ had less than $9^{\text {th }}$ grade numeracy skills, as measured by the WRAT-3.

Mean score (\% correct) on the 10 item PHLAT Spanish (PHLAT-10 Spanish) was $41.6 \%$ (SD 21.1\%; range 0-100\%). Table 2 describes the topics covered in the PHLAT-10, and the percent of parents who answered correctly for each item. Most (70.5\%) were able to refer to an ingredient list on a food label to determine whether a food was appropriate to give to their child, and $58.0 \%$ were able to refer to instructions from over-the-counter ibuprofen packaging to determine how many milliliters are in $1 / 2$ teaspoon of medicine. Fewer than half were able to read a liquid antibiotic prescription label and indicate how much medication to administer within an oral syringe (45.5\%) or to calculate the number of 2-ounce servings of juice in a 32-ounce can of juice (45.5\%). 33.0\% were able to read and comprehend breastfeeding information from a parent-education brochure published by the U.S. Department of Health and Human Services. $71.6 \%$ of parents were able to explain how to make a 4-ounce bottle of formula using powder-based formula, but only $15.9 \%$ were able to explain how to make a 4-ounce bottle of formula using concentrated formula. Of note, the instructions on the powder-based-formula label were presented in table format, and the instructions on the concentrated-formula label were presented in text format.

Correlations between caregiver characteristics and total PHLAT-10 score are shown in Table 3. Higher performance on the PHLAT-10 was significantly associated with greater years of education ( $\mathrm{r}=0.49)$, S-TOFHLA $(\mathrm{r}=0.53)$, and WRAT-3 Arithmetic $(\mathrm{r}=0.55)$ ( $\mathrm{p}<0.001$ for each). Higher performance on the PHLAT was less closely correlated, but still 
significantly associated, with increased confidence in filling out forms $(\mathrm{r}=0.18 ; \mathrm{p}=0.02)$ and decreased frequency of having someone help read medical information $(r=0.22 ; p=0.004)$.

Internal reliability of the PHLAT-10 Spanish was good (KR-20=0.61). Psychometric analyses suggested that the 10 PHLAT items were best explained by a single factor. Item 4 was removed due to poor factor loading. Item 3 was removed as the content of the question was no longer clinically recommended; physicians no longer recommend mixing Pedialyte with formula in cases of diarrhea. A shortened, 8-item scale (PHLAT-8) was highly correlated with the full, 10-item S-PHLAT $(\mathrm{r}=0.97, \mathrm{p}<0.001)$. The average score on the PHLAT-8 Spanish was mean (SD) 46.5\% (24.9\%). The correlation between the PHLAT-8 and parent characteristics was similar to the correlations between the full, 10-item PHLAT and parent characteristics (Table 3). Internal reliability of the PHLAT-8 was also comparable $(\mathrm{KR}-20=0.64)$. Each of the single survey items for self-assessed literacy skills $\left(\right.$ Chew et $\mathrm{al}^{27}$ ) were correlated with the PHLAT-8 score $(\mathrm{r}=0.22-0.23 ; \mathrm{p}<0.01)$.

\section{DISCUSSION}

This study demonstrates that like English-speaking caregivers, ${ }^{2}$ many Spanish-speaking caregivers have significant difficulty in understanding basic health information related to the care of their young children, and that differences in the way health information is presented appears to affect caregiver understanding. In addition, this study suggests that the Spanish version of the PHLAT, with its good reliability and construct validity, may be a helpful tool to evaluate the health literacy skills of parents of young children. To our knowledge, the PHLAT is the first assessment focused on examining the health literacy skills relevant to parents of young children, and the Spanish version of the PHLAT is the first assessment to examine these health-related parent skills among Spanish-speaking parents of young children. Availability of a validated scale in Spanish is important, given the growing population of Latinos in the US, as well as the unique needs of this at-risk population. ${ }^{23}$ Health literacy is being increasingly cited as a potentially important mediator of health disparities, ${ }^{1,24,29}$ reinforcing the need to develop and evaluate strategies to assess health literacy across diverse populations.

As seen with the English PHLAT-10, the Spanish PHLAT-10 (PHLAT-10 Spanish) has good reliability and validity as a test of literacy and numeracy skills of caregivers of young children. Higher PHLAT-10 Spanish scores were strongly associated with higher education, health literacy scores on the S-TOFHLA, as well as numeracy scores (WRAT-3 Arithmetic). Higher PHLAT scores were also associated with a self-reported higher level of confidence in filling out health forms and decreased frequency of needing help from others to understand health information. While income was not associated with PHLAT score in our sample as we had expected, this may have been due to a large percentage of parents who did not know, or refused to report, their income level. In addition, the income level of parents in this sample may have been too homogenous to allow for us to assess the relationship between PHLAT scores and income. Like the English PHLAT, the Spanish PHLAT has content validity, as the assessment items are based on actual materials that parents typically encounter in their health-related daily activities in caring for their young children. The shortened PHLAT-8 Spanish has similar reliability and validity, with the added benefit of decreased time burden for administration.

Interestingly, while few parents in our sample were categorized as having limited health literacy based on the S-TOFHLA, parent performance on the Spanish PHLAT had greater variability, a pattern also seen in our previously published analyses of parent performance on the English PHLAT. ${ }^{2}$ This may be related to a ceiling effect that has been previously noted with the S-TOFHLA. ${ }^{19,} 20$ The PHLAT may be more able to capture a broader range 
of functional health literacy skills (including document and quantitative skills) than the STOFHLA. ${ }^{2}$

Overall, the Spanish-speaking parents in our sample performed more poorly on the PHLAT-10 than the group of English-speaking parents we studied previously from a similar clinic population, with a mean of $42 \%$ (SD 21) and 68\% (SD 18) for Spanish and English speakers, respectively. ${ }^{2}$ This difference in the performance of English and Spanish-speaking subjects is a trend that has been seen in other studies in which Spanish language versions of health literacy assessments have been evaluated, including in studies of the TOFHLA and the Newest Vital Sign. ${ }^{18,21}$ The difference in mean performance on the PHLAT between the Spanish-speaking parents in our study, and the English-speaking parents in the prior study, is likely confounded by the disproportionately larger proportion of immigrant, low SES families with low educational achievement within the Spanish-speaking population we studied. It is notable, however, that even when results were stratified by education level, Spanish-speaking parents performed worse than English-speaking parents. Prior study has demonstrated that Latinos remain statistically significantly more likely to be categorized as having low health literacy even after controlling for confounders such as education, country of origin, English language proficiency, and income. ${ }^{1}$ The poor mean score in our study population is concerning, as the questions included in the PHLAT assessment represent typical tasks that pediatricians expect parents to be able to perform in order to care for their children's health.

This study has several limitations. In developing the PHLAT-Spanish, we chose to create Spanish-language equivalent materials in order to measure an individual's functional health literacy, distinct from the confounding factor of English-language proficiency. We acknowledge that this may overestimate an individual's 'real-world' functionality in situations where Spanish-language materials may not be available. In situations where assessment of such "real world" functioning of Spanish-speaking families is desired, use of the English language PHLAT assessment materials, or use of an additional measure of English-language proficiency, could be considered. Secondly, while the PHLAT can be used to assess parent health literacy and numeracy skills, we cannot assert that it correlates with clinically meaningful child health outcomes. A study to assess the relationship between the PHLAT and clinically meaningful outcomes, such as child immunization status, access to care, and child weight, is in progress.

This study was conducted using a convenience sample of Spanish-speaking caregivers recruited from pediatric clinics associated with four academic medical centers, and as such is subject to selection bias. While the results may be relevant to urban, low-income Latino populations, our findings may not be generalizable across the US Latino population, or with other clinic populations. In addition, no gold-standard assessment of parent health literacy currently exists. The health literacy measure we used, the S-TOFHLA, had little variability and limited our ability to validate our new measure. While we used the arithmetic section of the WRAT, a validated tool, to examine numeracy skills, we note that the WRAT has not been validated in Spanish. The WRAT-Arithmetic section, however, contains few words. We also recognize that subject performance on the PHLAT assessment may have been influenced by prior experience with assessment tasks, however we used the same approach in developing assessment materials as other existing validated health literacy assessments. ${ }^{2126}$ Finally, the PHLAT relies on written materials to assess parent health literacy and does not examine other important aspects within the complex construct of health literacy, such as verbal health literacy or navigation skills. Many health literacy assessments, however, including the most commonly used assessments in health literacy research, the TOFHLA $^{18}$ and the REALM, ${ }^{30}$ use subject performance on a written material-based health literacy assessment as a proxy measure for overall health literacy. 
Despite the above limitations, there are significant implications to our findings. Our study demonstrates that a large proportion of Spanish-speaking families have limited health literacy and numeracy skills, making it difficult for them to perform daily tasks related to the health-related care of their young children - including mixing formula, measuring liquid medication, and interpreting food labels. Inability to perform these basic tasks place children at risk for poor outcomes, including medication errors. ${ }^{1}$

While our findings suggest that the PHLAT may be a more optimal tool than the STOFHLA for assessing the health literacy skills of parents of young children, additional study is needed to better elucidate how this tool could be best used within the research or clinical setting. In particular, further study is needed to determine at what threshold a low PHLAT score is considered to be clinically meaningful.

The high rate of parent misunderstanding seen in our study further reinforces the need to improve the clarity with which existing health information is presented. ${ }^{2}$ Addressing this issue is consistent with the recommendations of the "National Action Plan to Improve Health Literacy," recently released by the US Department of Health and Human Services. ${ }^{31}$ Low-literacy strategies to improve parent understanding of health information - such as avoiding medical jargon and using pictographic information - should accompany languagesensitive and culturally sensitive efforts to serve the health needs of Latino families. ${ }^{32}, 33$

\section{WHAT'S NEW}

Few tools exist to assess the ability of Spanish-speaking parents to complete healthrelated literacy/numeracy tasks important for the care of their young children. The PHLAT-10 Spanish may help identify parents who would benefit from receiving lowliteracy child health information.

\section{Acknowledgments}

FUNDING: This research was supported with funding from the NICHD (R01 HD049794), and the Tennessee Department of Health Project Diabetes Initiative. This research was also supported in part by a grant under The Robert Wood Johnson Foundation Physician Faculty Scholars Program (Dr. Yin). Dr. White conducted this research with support from Meharry's CRECD program (1R25RR17577). Dr. Perrin is supported by an NIH career development award (K23 HD051817).

\section{Appendix 1}

Sample Spanish PHLAT questions, and associated original English language questions

\section{REFERENCES}

1. Yin HS, Johnson M, Mendelsohn AL, Abrams MA, Sanders LM, Dreyer BP. The health literacy of parents in the United States: a nationally representative study. Pediatrics. 2009; 124 Supplement_3:S289-S298. [PubMed: 19861483]

2. Kumar D, Sanders LM, Perrin EM, et al. Parental understanding of infant health information: Health literacy, numeracy, and the Parental Health Literacy Activities Test (PHLAT). Academic pediatrics. 2010; 10(5):309-316. [PubMed: 20674532]

3. Rothman RL, Yin HS, Mulvaney S, Co JPT, Homer C, Lannon C. Health literacy and quality: focus on chronic illness care and patient safety. Pediatrics. 2009; 124 Supplement 3:S315-S326. 2009. [PubMed: 19861486]

4. Rothman R, Housam R, Weiss H, et al. Patient understanding of food labels: The role of literacy and numeracy. American Journal of Preventive Medicine. 2006; 31(5):391-398. [PubMed: 17046410] 
5. U.S. Department of Health and Human Services. Healthy People 2010: understanding and improving health. 2nd edition. Washington, DC: US Government Printing Office; 2000 November.

6. Schwartzberg, JG.; Van Geest, JB.; Wang, CC., editors. Understanding Health Literacy: Implications for Medicine and Public Health. AMA Press; 2005.

7. Berkman, ND.; DeWalt, DA.; Pignone, MP., et al. Literacy and health outcomes. Rockville, MD: Agency for Healthcare Research and Quality; 2004.

8. Nielson-Bohlman, L.; Panzer, A.; Kindig, D., editors. Health literacy: a prescription to end confusion. Washington, DC: Institute of Medicine - National Academies Press; 2004.

9. DeWalt DA, Hink A. Health literacy and child health outcomes: A systematic review of the literature. Pediatrics. 2009; 124 Supplement_3:S265-S274. [PubMed: 19861480]

10. Yin HS, Mendelsohn AL, Wolf MS, et al. Parents' medication administration errors: Role of dosing instruments and health literacy. Archives of Pediatrics and Adolescent Medicine. 2010; 164(2):181-186. [PubMed: 20124148]

11. DeWalt D, Dilling M, Rosenthal M, Pignone M. Low parental literacy is associated with worse asthma care measures in children. Ambulatory Pediatrics. 2007; 7(1):25-31. [PubMed: 17261479]

12. Ross LA, Frier BM, Kelnar CJH, Deary IJ. Child and parental mental ability and glycaemic control in children with Type 1 diabetes. Diabetic Medicine. 2001; 18(5):364-369. [PubMed: 11472446]

13. Joint Commission. "What did the doctor say?": Improving health literacy to protect patient safety. Health Care at the Crossroads report. 2007

14. Institute of Medicine. Measures of Health Literacy: Workshop summary. Washington, DC: National Academies Press; 2009.

15. Nath CR, Sylvester ST, Yasek V, Gunel E. Development and validation of a literacy assessment tool for persons with diabetes. Diabetes Educator. 2001; 27(6):857-864. [PubMed: 12211925]

16. Jones M, Lee JY, Rozier RG. Oral health literacy among adult patients seeking dental care. J Am Dent Assoc. 2007; 138(9):1199-1208. [PubMed: 17785385]

17. Davis TC, Wolf MS, Arnold CL, et al. Development and validation of the rapid estimate of adolescent literacy in medicine (REALM-Teen): A tool to screen adolescents for below-grade reading in health care settings. Pediatrics. 2006; 118(6):e1707-e1714. [PubMed: 17142495]

18. Parker RM, Baker DW, Williams MV, Nurss JR. The test of functional health literacy in adults: a new instrument for measuring patients' literacy skills. Journal of General Internal Medicine. 1995; 10(10):537-541. [PubMed: 8576769]

19. Wolf MS, Feinglass J, Thompson J, Baker DW. In search of 'low health literacy': Threshold. vs. gradient effect of literacy on health status and mortality. Social Science \& Medicine. 2010; 70(9): 1335-1341. [PubMed: 20167411]

20. Pandit AU, Tang JW, Bailey SC, et al. Education, literacy, and health: Mediating effects on hypertension knowledge and control. Patient Education and Counseling. 2009; 75(3):381-385. [PubMed: 19442477]

21. Weiss BD, Mays MZ, Martz W, et al. Quick assessment of literacy in primary care: the newest vital sign. Annals of Family Medicine. 2005; 3(6):514-522. [PubMed: 16338915]

22. Lee S-YD, Bender DE, Ruiz RE, Cho YI. Development of an easy-to-use Spanish Health Literacy test. Health Services Research. 2006; 41(4 Pt 1):1392-1412. [PubMed: 16899014]

23. Kutner M, Greenberg E, Jin Y, Paulsen C, White S. The health literacy of America's adults: results from the 2003 National Assessment of Adult Literacy: National Center for Education Statistics: US Department of Education. 2006

24. Osborn CY, Paasche-Orlow MK, Davis TC, et al. Health literacy: an overlooked factor in understanding HIV health disparities. American Journal of Preventive Medicine. 2007; 33(5):374378. [PubMed: 17950402]

25. Wilkinson, G. WRAT3: Wide range achievement test administration manual. Wilmington, DE: Wide Range Inc; 1993.

26. Nurss, J.; Parker, R.; Baker, D. TOFHLA: Test of functional health literacy in adults. Snow Camp, NC: Peppercorn Books \& Press; 1995.

27. Chew LD, Bradley KA, Boyko EJ. Brief questions to identify patients with inadequate health literacy. Family Medicine. 2004; 36(8):588-594. [PubMed: 15343421] 
28. Sanders LM, Thompson VT, Wilkinson JD, Sanders LM, Thompson VT, Wilkinson JD. Caregiver health literacy and the use of child health services. Pediatrics. 2007; 119(1):e86-e92. [PubMed: 17200263]

29. Howard DH, Sentell T, Gazmararian JA. Impact of health literacy on socioeconomic and racial differences in health in an elderly population. Journal of General Internal Medicine. 2006; 21(8): 857-861. [PubMed: 16881947]

30. Davis TC, Crouch MA, Long SW, et al. Rapid assessment of literacy levels of adult primary care patients. Family Medicine. 1991; 23(6):433-435. [PubMed: 1936717]

31. US Department of Health and Human Services. National Action Plan to Improve Health Literacy. 2010

32. Doak, CC.; Doak, LG.; Root, JH. Teaching patients with low literacy skills. Philadelphia, PA: Lippincott Williams \& Wilkins; 1996.

33. Houts PS, Doak CC, Doak LG, Loscalzo MJ. The role of pictures in improving health communication: a review of research on attention, comprehension, recall, and adherence. Patient Education \& Counseling. 2006; 61(2):173-190. [PubMed: 16122896] 
Table 1

Caregiver characteristics

\begin{tabular}{|c|c|}
\hline Caregiver characteristic & Mean (SD) or n (\%) \\
\hline Age, y, mean (SD) & $27.7(6.2)^{l}$ \\
\hline Gender: Female & $157(89.2)$ \\
\hline Ethnicity: Hispanic & $174(98.9)$ \\
\hline Country of Origin: non-US born & $166(94.3)$ \\
\hline Limited English proficiency & $167(94.9)$ \\
\hline Relationship to Child: Mother & $154(87.5)$ \\
\hline \# of Children in Family, mean (SD) & $2.0(1.0)$ \\
\hline Age of youngest child, months & $8.9(7.2)$ \\
\hline \multicolumn{2}{|l|}{ Annual family income } \\
\hline$<\$ 19,999$ & $83(47.2)$ \\
\hline$\$ 20,000-39,999$ & $12(6.8)$ \\
\hline$\geq \$ 40,000$ & $6(3.4)$ \\
\hline Did not know/Refused & $75(42.6)$ \\
\hline Participation in WIC program & $155(88.1)$ \\
\hline \multicolumn{2}{|l|}{ Education } \\
\hline Less than high school & $108(61.4)$ \\
\hline High school or GED & $44(25.0)$ \\
\hline Some college or above & $24(13.6)$ \\
\hline \multicolumn{2}{|l|}{ Literacy (S-TOFHLA) } \\
\hline Inadequate & $28(15.9)$ \\
\hline Marginal & $12(6.8)$ \\
\hline Adequate & $136(77.3)$ \\
\hline \multicolumn{2}{|l|}{ Numeracy skills (WRAT-3) ${ }^{2}$} \\
\hline Fifth grade or less & $131(75.7)$ \\
\hline Sixth to eighth grade & $41(23.7)$ \\
\hline High school of above & $1(0.6)$ \\
\hline \multicolumn{2}{|l|}{ Confidence filling out forms on own } \\
\hline Extremely & $18(10.2)$ \\
\hline Quite a bit & $87(49.4)$ \\
\hline Somewhat & $38(21.6)$ \\
\hline A little bit & $33(18.8)$ \\
\hline
\end{tabular}




\begin{tabular}{|l|c|}
\hline Caregiver characteristic & Mean (SD) or n (\%) \\
\hline Never & $31(17.6)$ \\
Occasionally & $41(23.3)$ \\
Sometimes & $72(40.9)$ \\
Often & $11(6.3)$ \\
Always & $21(11.9)$ \\
\hline
\end{tabular}

WIC $=$ Special supplemental nutrition program for Women, Infants, and Children; S-TOFHLA $=$ Short Test of Functional Health Literacy in Adults; WRAT-3 = Wide Range Achievement Test - Third Edition;

1 M mother age; for fathers missing age, age imputed using mean father age. Without imputed ages, mean age (SD) 27.5 (6.0).

${ }^{2}$ Missing for 3 caregivers 
Table 2

PHLAT-10 question topics and results

\begin{tabular}{|c|c|c|c|}
\hline No. & $\begin{array}{l}\text { Original } \\
\text { No. } 1\end{array}$ & Question topic & $\begin{array}{l}\mathbf{N}(\%) \\
\text { correct }\end{array}$ \\
\hline 1 & 1 & Demonstrates how to make a 4-ounce bottle of formula using powder-based formula. & $126(71.6)$ \\
\hline 2 & 2 & Demonstrates how to make a 4-ounce bottle of formula using concentrated formula. & $28(15.9)$ \\
\hline $3^{2}$ & 3 & Demonstrates how to mix an 8-ounce bottle of half Pedialyte and half powdered formula. & $11(6.3)$ \\
\hline $4^{2}$ & 6 & Interprets a growth chart where the baby is at the $25^{\text {th }}$ percentile for weight. & $67(38.1)$ \\
\hline 5 & 10 & Refers to an ibuprofen container to determine how many milliliters are in $1 / 2$ teaspoon of medicine. & $102(58.0)$ \\
\hline 6 & 12 & Refers to an ingredient list on a food label to determine whether a food is appropriate to give to their child. & $124(70.5)$ \\
\hline 7 & 16 & $\begin{array}{l}\text { Reads a liquid antibiotic prescription label and demonstrates how much medication to administer within an } \\
\text { oral syringe. }\end{array}$ & $80(45.5)$ \\
\hline 8 & 17 & Calculates the number of 2-ounce servings of juice in a 32 -ounce can of juice. & $80(45.5)$ \\
\hline 9 & 18 & $\begin{array}{l}\text { Interprets a food label to determine whether it meets WIC guidelines of being } 100 \% \text { fruit juice and contains at } \\
\text { least } 30 \mathrm{mg} \text { of vitamin } \mathrm{C} \text { per } 100 \mathrm{~mL} \text { of juice, or } 120 \% \text { of the daily value of vitamin C. }{ }^{3}\end{array}$ & $56(31.8)$ \\
\hline 10 & 19 & $\begin{array}{l}\text { Reads and comprehends information about breastfeeding (brochure from the Department of Health and } \\
\text { Human Services). }\end{array}$ & $58(33.0)$ \\
\hline
\end{tabular}

${ }^{1}$ From original full length, 20-item PHLAT (PHLAT-20)

2 Items removed for the shortened, 8-item PHLAT (PHLAT-8)

3 Parent was presented with the following information: "The WIC (Women, Infants, and Children) Program serves to provide nutritious foods and information to new mothers, infants, and young children. To be eligible for WIC, juices must be $100 \%$ fruit or vegetable juice. They must also contain 30mg of Vitamin C per $100 \mathrm{ml}$ of juice, or $120 \%$ of Daily Value of Vitamin C. Would the juice with the Nutrition Facts below be eligible for WIC? (Please see label)." 
Table 3

Relationship between caregiver characteristics and PHLAT-10 Spanish (10 item) and PHLAT-8 Spanish (8 item).

\begin{tabular}{|c|c|c|c|c|}
\hline & \multicolumn{2}{|c|}{ PHLAT-10 Spanish } & \multicolumn{2}{|c|}{ PHLAT-8 Spanish } \\
\hline & $\begin{array}{l}\text { Mean (SD) or } \\
\text { Correlation (r) }\end{array}$ & $P$ value & $\begin{array}{l}\text { Mean (SD) or } \\
\text { Correlation (r) }\end{array}$ & $P$ value \\
\hline Caregiver age, years & -0.07 & 0.4 & -0.08 & 0.3 \\
\hline Age of youngest child (mo) & 0.02 & 0.7 & 0.02 & 0.8 \\
\hline Race / ethnicity & & 0.7 & & 0.6 \\
\hline Hispanic $(\mathrm{n}=174)$ & $42(21)$ & & $47(25)$ & \\
\hline Other $(n=2)$ & $35(50)$ & & $38(53)$ & \\
\hline Annual family income ${ }^{l}$ & & 0.8 & & 0.9 \\
\hline$<19,999$ & $47(21)$ & & $52(26)$ & \\
\hline$\$ 20,000-39,999$ & $50(21)$ & & $55(26)$ & \\
\hline$\geq 40,000$ & $52(23)$ & & $56(23)$ & \\
\hline Participation in WIC Program & & 0.3 & & 0.5 \\
\hline Yes & $41(21)$ & & $46(25)$ & \\
\hline No & $46(20)$ & & $50(25)$ & \\
\hline Education & & $<0.001$ & & $<0.001$ \\
\hline Less than high school & $35(20)$ & & $39(24)$ & \\
\hline High school or GED & $47(21)$ & & $53(24)$ & \\
\hline Some college or above & $60(14)$ & & $68(15)$ & \\
\hline Education, years & 0.49 & $<0.001$ & 0.48 & $<0.001$ \\
\hline Literacy (S-TOFHLA) & & $<0.001$ & & $<0.001$ \\
\hline Inadequate / Marginal & $26(14)$ & & $27(16)$ & \\
\hline Adequate & $46(21)$ & & $52(24)$ & \\
\hline Raw S-TOFHLA score & 0.53 & $<0.001$ & 0.55 & $<0.001$ \\
\hline Numeracy skills (WRAT-3) & & $<0.001$ & & $<0.001$ \\
\hline Fifth grade or less & $36(19)$ & & $40(23)$ & \\
\hline Sixth to eighth grade & $58(19)$ & & $66(21)$ & \\
\hline Ninth grade or above & $60^{2}$ & & $75^{2}$ & \\
\hline Standard WRAT score & 0.55 & $<0.001$ & 0.54 & $<0.001$ \\
\hline Confidence filling out forms on own ${ }^{3}$ & 0.18 & 0.02 & 0.22 & 0.004 \\
\hline How often have someone help read medical information 4 & 0.22 & 0.004 & 0.23 & 0.002 \\
\hline PHLAT-10 Spanish score & --- & --- & 0.97 & $<0.001$ \\
\hline
\end{tabular}




\footnotetext{
${ }^{1}$ Missing for 75 caregivers who refused / did not know annual income

2 Only one person categorized as having HS or above numeracy; no SD calculated

${ }^{3}$ Answer choices reverse ordered for analysis in the following manner: "not at all," "a little bit," "somewhat," "quite a bit," "extremely"

${ }^{4}$ Answer choices reverse ordered for analysis in the following manner: "always," "often," "sometimes," "occasionally," "never"
} 